\title{
Da Lei de Titius-Bode ao embate entre a Matéria Escura e a Dinâmica de Newton Modificada: uma trajetória epistemológica pela Astronomia
}

From Titius-Bode's Law to the dispute between Dark Matter and Modified Newton's Dynamics: an epistemological trajectory through Astronomy

\author{
Nathan Willig Lima ${ }^{*} @$, Alan Alves-Brito ${ }^{2} @$, Matheus Monteiro Nascimento ${ }^{1 @}$ \\ ${ }^{1}$ Universidade Federal do Rio Grande do Sul, Instituto de Física, Porto Alegre, RS, Brasil. \\ ${ }^{2}$ Universidade Federal do Rio Grande do Sul, Departamento de Astronomia, Porto Alegre, RS, Brasil.
}

\begin{abstract}
Recebido em 28 de outubro de 2021. Revisado em 11 de janeiro de 2022. Aceito em 19 de janeiro de 2022.
Nos cursos de licenciatura, usualmente, as discussões sobre Epistemologia são feitas de forma desconectada das discussões técnicas, muitas vezes realizadas apenas em disciplinas específicas. Buscando romper com esse abismo entre os conteúdos técnicos e pedagógicos das licenciaturas em Física, apresentamos uma análise de um curso de extensão sobre Astrofísica e Epistemologia, oferecido para professores de ciências e licenciandos de Física. Nesse curso, diferentes episódios da Astronomia e Astrofísica foram discutidos à luz de diferentes concepções epistemológicas. Nosso objetivo era permitir que os alunos refletissem sobre suas próprias concepções, confrontando-as com as diferentes possibilidades apresentadas. Para avaliar a intervenção, foi realizado um préteste e pós-teste, em que os participantes expressavam sua concordância com 10 enunciados sobre natureza da ciência. As respostas foram analisadas usando o método estatístico de Escalonamento Multidimensional. Nossos resultados mostram que, inicialmente, as respostas não apresentavam consistência interna e os participantes exibiam o mesmo grau de concordância em relação a visões concorrentes sobre a natureza da ciência. Após o curso, os participantes passaram a se posicionar de forma mais coerente, concordando com características de uma mesma visão epistemológica e se afastando de visões concorrentes.
\end{abstract}

Palavras-chave: Epistemologia, Astronomia, Forrmação de professores.

In undergraduate courses, discussions on Epistemology are usually made disconnected from technical discussions, often carried out only in specific disciplines. Seeking to break this chasm between the technical and pedagogical contents of Physics degrees, we present an analysis of na outreach course on Astrophysics and Epistemology, offered to science teachers and Physics undergraduates. In this course, different episodes of Astronomy and Astrophysics were discussed accordingly to epistemological conceptions. Our objective was to allow students to reflect on their own conceptions, confronting them with the different possibilities. To evaluate the intervention, a pre-test and post-test were carried out, in which the participants expressed their agreement with 10 statements about the nature of science. Responses were analyzed using the statistical method of Multidimensional Scaling. Our results show that, initially, the answers lacked internal consistency and the participants showed the same degree of agreement regarding competing views on the nature of science. After the course, the participants began to position themselves more coherently, agreeing with characteristics of the same epistemological vision and moving away from competing visions.

Keywords: Epistemology, Astronomy, Teacher Education.

\section{Introdução}

O papel da Educação em Ciências na Educação Básica tem sido fonte de disputas entre defensores de diferentes visões de mundo e modelos pedagógicos. De uma forma geral, entretanto, é possível encontrar a preocupação por parte dos pesquisadores da área de Ensino com relação a conceber a educação científica como um caminho para fomentar a formação para a cidadania [1, 2]. Conforme apontado por Pinhão e Martins [3], entretanto,

\footnotetext{
*Endereço de correspondência: dionipastorio@hotmail.com
}

o conceito de cidadania é polissêmico e, portanto, enseja diferentes concepções político-pedagógicas.

Em especial, pode-se reconhecer que o exercício da cidadania, em sua forma plena, pode ser associado ao exercício da autonomia política e epistêmica, a qual se traduz pela possibilidade de decidir ou participar da tomada de decisão sobre temas socialmente relevantes 4. Ademais, como discutido por Latour [5, 6], muitos dos temas, hoje, socialmente relevantes não são apenas sociais, mas também técnicos ou científicos. Como devemos agir em meio à pandemia da COVID19? Como devemos nos posicionar frente ao aquecimento 
global? Quais são as melhores medidas econômicas para diminuir a desigualdade social no Brasil? Todas essas questões têm em comum, além do fato de serem socialmente relevantes, a especificidade de que são, usualmente, respondidas por especialistas, sejam eles epidemiologistas, cientistas ambientais ou economistas. Assim, para que um cidadão possa, de fato, exercer sua cidadania plena, podendo posicionar-se sobre os diferentes temas sociocientíficos, é importante que ele entenda não somente conceitos científicos mas como a própria ciência funciona, quais suas características, práticas, valores, limitações, potencialidades, disputas, ensejando a noção de que é necessário promover uma alfabetização científica [7-10].

Existem muitas formas de se fazer tais discussões [1] e, em especial, a inserção de tópicos de história e filosofia da ciência pode ser uma forma potente de promover a reflexão sobre "Natureza da Ciência" (NdC) [12]14], podendo se explorar uma ou mais das diferentes dimensões epistêmicas e sociais da ciência. Dentro desse contexto, desde o final dos anos oitenta, a área de Educação em Ciências tem apresentado uma preocupação explícita com a inserção da História e Filosofia da Ciência (HFC) na Educação Científica [15] como uma forma de ressignificar o seu papel, a qual tem sido uma tendência crescente desde então [16].

Diferentes perspectivas foram adotadas para discutir não apenas a $\mathrm{NdC}$ mas também as relações entre Ciência, Tecnologia e Sociedade (CTS) promovendo uma concepção mais ampla do conhecimento científico e da prática científica do que a visão de mundo oferecida pelo ensino tradicional [17. Para ter uma visão do cenário geral de pesquisas nesta área, Aikenhead [18] apresenta uma ampla revisão sobre HFC e CTS em Educação Científica, e Abd-El-Khalick e Lederman 19 apresentam uma revisão sobre o impacto das estratégias nas concepções de ciência do professor. No caso do Ensino de Física, especificamente, ainda há poucos trabalhos nessa direção [20].

Apesar desses esforços de pesquisa, é sabido que a área de Ensino de Física tem se mantido predominantemente associada a uma visão positivista 21] e até mesmo o ensino da Física contemporânea (que poderia ter tido alguma influência de novas tendências didáticas) segue tal concepção 22. Assim, propostas pedagógicas construídas a partir de visões epistemológicas alternativas ao positivismo são fundamentais para uma legítima formação para a cidadania.

Se, por um lado, o discurso predominante do Ensino de Física reforça a ciência como a detentora do monopólio de verdades imutáveis, por outro lado, acompanhamos nas mídias e redes sociais a total dissolução do conceito de verdade e, talvez, a maior desconfiança com relação à capacidade da ciência em resolver problemas dos últimos tempos - o que tem originado o aumento das perspectivas anticiência em todo o mundo [23, motivadas por interesses econômicos, como o movimento que nega o aquecimento global antropogênico [24].
É importante ressaltar que tais movimentos se valem, eventualmente, de argumentos originalmente articulados na Sociologia e na Filosofia da Ciência para desacreditar o conhecimento científico bem estabelecido sobre o meio ambiente, manipulando a opinião pública - o que é conhecido na Sociologia da Ciência como o dilema do "aliado errado". Para Bruno Latour (considerado protagonista das "guerras da ciência"), é hora de a ciência recuperar o respeito, sem, contudo, voltarmos a adotar a velha perspectiva absolutista 25 .

Nesse sentido, nunca se fez tão necessário discutir ciência e natureza da ciência na Educação Básica e na formação de professores. O grande desafio, como aponta Latour, é apresentar a ciência livre do absolutismo epistemológico, que nega as dimensões sociais e políticas da própria ciência, sem com isso recair em uma visão relativista - o que poderia nos levar ao caminho obscuro da pós-verdade e das fake news [26]. A crise da pandemia da COVID-19 evidenciou de que maneira o absolutismo epistemológico e o relativismo andam lado a lado, assim como ciência e política.

Trazer a discussão da natureza da ciência para a Educação Básica e para a formação de professores não é, portanto, apenas fruto de interesse acadêmico, mas uma necessidade da sociedade contemporânea. Precisamos decidir sobre questões importantes como aquecimento global, uso de vacinas, crise energética, entre tantos outros temas. Entender as contribuições que a ciência pode dar para tais decisões bem como suas limitações é de extrema relevância e deve ser um dos focos da Educação Básica e da formação de professores.

Existem, certamente, muitas estratégias e temas que podem ser adotados para alcançar esse objetivo [27. 35]. No presente artigo, trazemos uma análise sobre um caminho possível (entre tantos outros): partindo de alguns temas e episódios da História da Astronomia, discutimos diferentes visões epistemológicas.

O diferencial dessa proposta é que ela não é uma apresentação de visões epistemológicas em uma forma abstrata; mas uma apresentação de temas da história da Astronomia interpretados à luz de diferentes visões epistemológicas, organizada para ser utilizada em cursos de licenciatura em Física ou em cursos de formação de professores. Uma vez que há estudos que apontam que disciplinas isoladas de história e epistemologia não são suficientes para impactar a prática docente [36], ainda que sejam importantes, o presente trabalho contribui com a análise de uma intervenção didática que rompe com o abismo entre as disciplinas pedagógicas e técnicas que por muito tempo, infelizmente, marcou a identidade das licenciaturas em Física [37]. Em especial, os episódios apresentados na intervenção seguem tanto uma cronologia na história da Astronomia como na história da filosofia da ciência - em diálogo com obras típicas da área de Filosofia da Ciência [38.

Entendemos que essa proposta possui os seguintes pontos positivos: a) tópicos de Astronomia e Astrofísica, em geral, costumam despertar grande interesse nos 
alunos; b) a discussão conceitual, histórica e epistemológica é integrada em uma narrativa única; c) conseguimos partir de temas tradicionais da Educação Básica (como leis de Newton) e chegar em tópicos de Física contemporânea (como a hipótese da matéria escura) - o que pode viabilizar a transposição didática a ser feita pelos professores que passarem por essa intervenção, auxiliando no sentido de renovar o currículo escolar, e d) ressaltamos, na narrativa, a produção epistemológica e científica brasileira em oposição a uma postura usual, que adota apenas a produção europeia e norte-americana como válida e relevante.

Nosso objetivo, portanto, é apresentar a intervenção didática que foi construída e narrar alguns resultados obtidos em um curso de extensão para professores de ciências e para licenciandos, promovendo algumas reflexões para área de Ensino de Física. Para tanto, na seção 2 , discutimos questões teóricas subjacentes à construção da intervenção didática, apresentamos sua estruturação de uma forma geral e explicamos as escolhas feitas para avaliar a intervenção didática. Na seção 3 relatamos a intervenção didática e discutimos alguns resultados obtidos, promovendo reflexões para área de Ensino de Física. Por fim, na seção 4 apresentamos nossas considerações finais. No Apêndice 1, apresentamos o material de apoio criado para o curso. No Apêndice 2, apresentamos o instrumento de avaliação do curso.

\section{Design da Intervenção Didática: Concepção Pedagógica, Estruturação da Intervenção Didática e Método para Avaliação do Processo}

Alinhando-se à visão de que a formação para cidadania demanda o fomento da reflexão sobre elementos da Natureza da Ciência, incluindo, obviamente, sua dimensão epistemológica, o objetivo pedagógico dessa intervenção é permitir que os alunos reflitam sobre diferentes critérios de demarcaçã $\complement^{1}$ a partir de temas da História da Astronomia.

Assim, nosso objetivo não é defender uma visão epistemológica específica, mas permitir que os alunos entrem em contato com diferentes visões, confrontandoas com suas próprias perspectivas e comparando-as entre si, identificando as potencialidades e limitações de tais visões. Nesse sentido, nosso objetivo não é também que os alunos ganhem um conhecimento enciclopédico sobre Epistemologia, mas que, de fato, reflitam sobre a história da ciência e mobilizem diferentes concepções

\footnotetext{
1 Critérios de demarcação são aqueles utilizados para distinguir o que é ciência de não-ciência. O critério de demarcação não é necessariamente equivalente a um critério de significação, que distingue verdade de falsidade [42. De uma forma geral, epistemólogos absolutistas defendem que há critérios de demarcação nítidos e objetivos, enquanto epistemólogos relativistas defendem a acidentalidade dos critérios de demarcação, entendo-os como frutos de construções socioculturais.
}

para explicar a evolução de conceitos e teorias científicas. Em outras palavras, alinhando-nos à concepção vygotskiana, pretendemos fomentar nos alunos o desenvolvimento do processo de "apropriação" das visões epistemológicas 39. Deve-se ressaltar, entretanto, que apropriação é um processo longo, que, virtualmente, se estende pela vida toda. Assim, pretendemos apenas fomentar uma discussão inicial que auxilie os alunos nesse processo. Nesse sentido, a apropriação de tais visões demanda uma reflexão profunda e contínua, a qual deve permear todo o currículo da licenciatura e prosseguir em cursos de formação continuada.

Para que tal reflexão possa ser fomentada, pelo menos em um nível preliminar, na intervenção didática realizada, privilegiamos a possibilidade de os alunos enunciarem suas visões de ciência e confrontarem-nas com as visões apresentadas, exercitando, assim, a apropriação dos recursos semióticos (como o uso lexical adequado) - ganhando, preliminarmente, domínio sobre tais recursos [40, 41].

Por esse motivo, a sequência didátice ${ }^{2}$ iniciou com um questionário, no qual são verificadas diferentes percepções dos alunos sobre aspectos da Natureza da Ciência. Logo depois, foi realizado um diálogo inicial, no qual os alunos foram convidados para expressar sua visão sobre o que é a ciência e o que diferencia ciência de não-ciência. Como esperado, muitas das concepções apresentadas alinham-se com a visão "verificacionista' 3 de ciência.

Assim, nossa primeira discussão consistiu em apresentar a Lei de Titius-Bode e discutir como ela pode ser entendida à luz da visão verificacionista. A Lei de Titius-Bode relaciona a ordem dos planetas com seu distanciamento ao Sol. Uma vez estabelecida tal lei com os dados até Saturno, pode-se prever qual seria a distância do próximo planeta. De fato, "verifica-se" que a lei prevê com boa precisão a distância de Urano. Segundo a visão verificacionista, pode-se dizer, portanto, que a Lei de Titius-Bode é verdadeira. Entretanto, as observações para Netuno já discordam significativamente do que é previsto pela lei.

Assim, discutimos que uma afirmação científica, mesmo quando verificada e "comprovada" por medidas experimentais ou observacionais, ainda sim pode ser contestada por novos experimentos ou observações. Nessa discussão, apontamos, portanto, algumas limitações que o posicionamento epistemológico verificacionista pode ter - o que enseja uma nova proposta, o "refutacionismo".

Opondo-se ao verificacionismo, Popper 42 propõe que toda teoria científica não é aquela que é verificada por

\footnotetext{
2 O material de apoio da sequência didática está no Apêndice 1. ${ }^{3}$ Verificacionismo é a tendência epistemológica que defende que os enunciados científicos podem ser verificados ou comprovados. De uma forma genérica, uma vez que uma tese científica é apresentada, basta-se realizar o teste experimental, que, concordando com a tese, comprova-a. Essa visão segue presente no que Chalmers 38 denomina de visão de senso comum da ciência.
} 
dados experimentais ou observacionais, mas toda aquela para a qual pode-se montar um experimento crucial capaz de a refutar. Ou seja, a existência de Deus não pode ser considerada uma tese científica, visto que não é possível montar um experimento que a refute. Por outro lado, podemos tentar montar um experimento que refute previsões das Leis de Newton, logo elas são cientificas. Assim, segundo Popper [42, devemos montar tal experimento. Caso ele concorde com a teoria, não podemos dizer que a teoria foi provada, mas apenas corroborada. Por outro lado, se o experimento discorda da teoria, essa deve ser refutada e abandonada.

Na segunda discussão, partimos das leis de Kepler e das Leis de Newton para chegar na Lei da Gravitação Universal. Propomos, então, a seguinte pergunta: "a Lei da Gravitação Universal é científica?" Para que ela seja científica, na perspectiva popperiana, devemos ser capazes de montar um experimento crucial capaz de a refutar. Para isso, apresentamos o conceito de "curva de rotação" e propomos um teste crucial para verificar a validade da Lei da Gravitação Universal a partir de dados obtidos de curvas de rotação das Galáxias.

Mostramos que a previsão da Lei da Gravitação Universal para o comportamento da curva de rotação da galáxia não é compatível com a curva obtida experimentalmente. Se usamos a proposta de Popper 42 rigidamente, concluímos que a Lei da Gravitação Universal não é científica.

Isso evidencia que tal proposta epistemológica pode não traduzir corretamente aquilo que entendemos por científico. Para olhar esse problema por outro aspecto, apresentamos a perspectiva epistemológica de Lakatos 43 e discutimos como que o problema da curva de rotação das galáxias dá origem a dois programas de pesquisa distintos, o programa da Dinâmica de Newton Modificada (em inglês, MOND -Modified Newton Dynamics) e o programa da Matéria Escura. Em especial, discutimos que toda vez que uma teoria discorda de experimentos, não há uma refutação sumária da teoria, visto que os dados experimentais também dependem de outras construções teóricas. Assim, tudo que podemos dizer é que há uma inconsistência teórica. Quando a previsão da Lei da Gravitação Universal obtida a partir dos dados de luminosidade das estrelas das galáxias não concorda com as observações, podemos sugerir que o que está errado são as leis de Newton (o que deu origem ao MOND) ou que o que está errado é a relação entre massa e luminosidade (o que deu origem ao conceito de matéria escura). Cada um desses dois programas possui seu núcleo duro (tese de que não abre mão) e um cinturão protetor (conjunto de teses que pode abandonar no caso de um experimento a contrariar). Assim, o que é científico não é uma teoria, mas um programa de pesquisa. Programas de pesquisa que são continuamente corroborados e preveem corretamente novos experimentos são denominados de progressivos, enquanto programas que precisam continuamente se corrigir, são incapazes de fazer previsões corretas, são chamados de regressivos.

Um problema para o modelo de Lakatos, entretanto, é que o volume de produções realizadas na ciência contemporânea torna difícil perceber, em algumas situações, quais programas são progressivos e quais são regressivos. Em especial, no caso do tema em discussão, a maioria dos alunos presente já havia ouvido falar sobre matéria escura; mas ninguém conhecia o MOND. Assim, parece que a matéria escura tem um status mais bem estabelecido que o MOND, apesar de haver publicações que tentam explicar os dados astronômicos por meio da modificação da dinâmica de Newton.

Por isso, trouxemos uma última discussão, apresentando alguns conceitos relacionados ao estudo de redes em ciências [44, 45. Nessa discussão, mostramos como os grupos de pesquisa do programa do MOND e da matéria escura bem como suas produções se relacionam em redes complexas. Mais especificamente, trouxemos dados sobre números de publicações, número de citações e fator de impacto de revistas que publicam artigos dos dois programas. Ao fazer tal discussão nosso objetivo era mostrar que mesmo a matéria escura sendo um conceito amplamente difundido na comunidade científica e, até mesmo, na sociedade, a ciência é tão complexa que é possível haver um programa de pesquisa concorrente (como o MOND) que também tem relativo sucesso ao descrever os dados empíricos. Ao fazer tal apresentação, não temos como objetivo defender um programa de pesquisa ou outro, mas mostrar que, atualmente, a ciência é tão complexa e extensa que é possível avançar em programas de pesquisa concorrentes. Por fim, foi implementado, novamente, o teste com afirmações sobre natureza da ciência.

Toda intervenção foi realizada em um total de 12 horas de aulas. A estrutura da intervenção é representada em um fluxograma na Figura 11. O material de apoio da intervenção se encontra no Apêndice 1.

\section{Análise da Intervenção Didática}

A intervenção didática consistiu em um curso de extensão, de 12 horas de duração, realizado em três dias consecutivos, e oferecido em uma universidade federal, para professores da educação básica e alunos de cursos de licenciatura. Ao todo, o curso contou com 46 participantes.

Além do questionário inicial e final, os alunos tiveram a oportunidade de expressar suas concepções respondendo a perguntas sobre o tema oralmente ou usando uma ferramenta digita $]^{4}$ de forma que, a todo momento,

\footnotetext{
${ }^{4}$ Para respostas a perguntas objetivas, ao longo do curso, foi usada a plataforma kahoot.com. Para verificar a concepção inicial sobre Natureza da Ciência, foi solicitado que cada aluno escrevesse cinco palavras - formando uma nuvem de palavras automaticamente com a plataforma mentimeter.com.
} 




Figura 1: Estrutura da intervenção didática.

havia espaço para interação entre os professores e os alunos. O objetivo do curso, como já mencionado, não era defender uma visão epistemológica específica, mas promover o diálogo e a reflexão sobre as diferentes concepções epistemológicas, permitindo que os alunos confrontassem suas próprias visões com os exemplos trazidos e relacionasse as diferentes visões entre si.

Em especial, o diferencial desse curso foi não apresentar as visões epistemológicas de uma forma enciclopédica ou abstrata; mas, sim, hibridizada com a análise de temas da Astronomia. Por se tratar de uma intervenção exploratória, decidimos fazer uma avaliação global sobre os efeitos do curso sobre o grupo como um todo e não sobre a evolução de sujeitos específicos. Por isso, optamos por desenvolver um instrumento de avaliação quantitativo, em que os participantes poderiam expressar sua concordância ou discordância com relação a dez afirmações sobre natureza da ciência, usando uma escala likert de 0 a 10 (Apêndice 2). Os participantes responderam ao questionário em dois momentos diferentes, antes e depois do curso. Denominaremos estes momentos de pré e pós teste. Alguns participantes não puderam participar de todo o evento e, portanto, apenas 38 participantes responderam o pré e o pós teste. Mesmo reconhecendo as limitações de um método quantitativo de pesquisa, optamos por tal estratégia, pois a consideramos suficiente para ter uma primeira avaliação sobre qual o tipo de impacto que a estratégia didática adotada poderia ter sobre o grupo.
Como se tratou de um instrumento construído especialmente para esta investigação, se fez necessário primeiramente determinar o coeficiente de fidedignidade do questionário. Para tanto, utilizou-se o índice de confiabilidade de Cronbach 46, mais conhecido como alfa de Cronbach. Este coeficiente assume valores entre 0 e 1 , sendo que quanto mais perto do valor 1 , maior a consistência interna do instrumento. A literatura indica que valores entre 0,7 e 0,9 para o coeficiente são aceitáveis, especialmente para questionários com escala semelhante a utilizada nesta investigação [47. 48. A análise da confiabilidade resultou um valor de $\alpha=0,666$ para o pré-teste e $\alpha=0,678$ para $\mathrm{o}$ pós-teste, valores considerados baixos. Retirando-se o item 8 do questionário conseguimos obter um valor de $\alpha=0,760$, tanto para o pré-teste como para o pós-teste.

Após a análise da consistência interna do instrumento podemos analisar as respostas atribuídas pelos participantes do curso aos itens do questionário. A Tabela 1 mostra o enunciado de cada um dos itens do questionário, bem como uma expressão que sintetiza o tema de cada item. Esta expressão, ou palavra-chave, destaca o aspecto da ciência que está sendo evocado no item. Por exemplo, a segunda pergunta do questionário avalia se o estudante concorda com a afirmação de que as teorias científicas não são verdades absolutas, pois são desenvolvidas por seres humanos; assim, a expressão "construção humana" foi associada a este item. 
Tabela 1: Detalhamento dos itens do questionário e palavras-chave que melhor representam os temas dos itens.

\begin{tabular}{lll}
\hline Item & Enunciado & Palavra-chave \\
\hline 1 & $\begin{array}{l}\text { O método científico consiste em partir de observação da natureza, encontrar um } \\
\text { problema, elaborar hipóteses, sistematizar os dados, construir leis, e testar as leis. }\end{array}$ & Linear \\
\hline 2 & $\begin{array}{l}\text { Teorias científicas não são verdades porque são construídas pelos seres humanos; as } \\
\text { sociedades mudam e, portanto, teorias hoje consideradas revolucionárias podem se } \\
\text { tornar superadas e até abandonadas no futuro. }\end{array}$ & $\begin{array}{l}\text { humanão } \\
\text { huma }\end{array}$ \\
\hline 3 & $\begin{array}{l}\text { Para desenvolver uma teoria científica, o cientista deve tentar abdicar de } \\
\text { concepções e crenças pessoais, buscando fazer afirmações puramente empíricas. }\end{array}$ & Impessoalidade \\
\hline 4 & $\begin{array}{l}\text { Condições sociais, culturais, e políticas predominantes em determinados momentos } \\
\text { (períodos históricos) influenciam a ciência. }\end{array}$ & Ciência \& \\
\hline 5 & A ciência é universal e imparcial. & Neutralidade \\
\hline 6 & $\begin{array}{l}\text { Fred Hoyle foi um cientista que não aceitou a teoria do Big Bang quando de sua } \\
\text { proposição. Este fato é suficiente para constituir uma controvérsia científica e } \\
\text { colocar em dúvida a própria teoria. }\end{array}$ & $\begin{array}{l}\text { Prática } \\
\text { individual }\end{array}$ \\
\hline 7 & Existe uma distinção clara entre ciência e pseudociência. & Demarcação \\
\hline 9 & Todo conhecimento científico é comprovado empiricamente. & Comprovação \\
\hline 10 & $\begin{array}{l}\text { Uma determinada teoria fez previsões sobre como um fenômeno deveria se } \\
\text { comportar. Ao fazer o teste experimental, percebeu-se que a previsão teórica } \\
\text { estava errada. Nesse caso, devemos abandonar a teoria e busca outra que explique }\end{array}$ & Refutacionista \\
& $\begin{array}{l}\text { o fenômeno corretamente. } \\
\end{array}$ & \\
\hline
\end{tabular}

Com o objetivo de obter um panorama inicial sobre os dados obtidos, foram construídos histogramas para todos os itens do pré-teste e do pós-teste, conforme ilustra a Figura 2(a) e (b). A partir dos histogramas podemos perceber variações na distribuição das respostas atribuídas pelos participantes. Em alguns casos a variabilidade da distribuição é mais significativa, sendo possível percebê-la a partir de uma simples inspeção visual. Contudo, em geral, como se observa na Figura 2 . não é possível fazer uma avaliação mais aprofundada e rigorosa das respostas dos participantes apenas com o suporte dos histogramas. As variações são sutis e difíceis de serem observadas sem suporte de ferramentas adequadas. Portanto, realizamos uma análise estatística chamada de Escalonamento Multidimensional (Multidimensional Scaling - EMD) a fim de melhor compreender o significado da variação das respostas entre o pré-teste e o pós-teste do questionário.

O Escalonamento Multidimensional é uma técnica estatística desenvolvida para mapear a distância entre objetos 49. A partir do EMD é possível transformar a similaridade entre casos em distâncias que podem ser projetadas em um espaço multidimensional. Em muitos casos a projeção ocorre em um plano bidimensional. Neste espaço de projeção, cada evento (ou caso) é um ponto diferente e a distância entre os pontos indica a semelhança entre os casos. Em outras palavras, quanto mais próximos dois pontos estiverem no mapa, mais similares são os casos representados pelos pontos. O EMD é uma técnica muito utilizada na área da ecologia, especialmente para o mapeamento de espécies [50]. Na área da Educação em Ciências, o EMD se apresenta como uma potente ferramenta analítica [51], utilizada, por exemplo, para o mapeamento cognitivo [52, levantamento da similaridade entre conceitos físicos [53], para o estudo de representações sociais sobre as ciências [54].
Para maiores detalhes sobre a história, a construção teórica e aplicações do EMD, consultar o livro de Young [55].

Em nossa investigação, utilizamos o EMD para tentar encontrar alterações nas visões sobre a ciência dos participantes do curso, a partir da similaridade entre os itens do questionário. Como exposto previamente, foram associadas diferentes palavras-chave aos itens do questionário, dependendo do tema analisado, conforme indicado na Tabela 11. Considerando que cada um dos nove itens abordava um aspecto diferente sobre a ciência, alguns teoricamente semelhantes e outros totalmente contrastantes, foi possível analisar se o curso em questão conseguiu mostrar para os participantes os diferentes aspectos que transpassam e perpassam os agentes relacionados com a ciência. Todas as análises quantitativas foram realizadas no ambiente de programação RStudio 56 .

O EMD aplicado aos dados do pré-teste, ou seja, antes do curso, mostram uma dispersão muito grande no entendimento dos estudantes sobre a ciência, conforme visualizado no mapa da Figura 3 Não há grande similaridade entre os itens do questionário nesta etapa da avaliação. Tal quadro é muito diferente do observado nos dados do pós-teste. Após a realização do curso, os estudantes demonstraram desenvolver uma visão consistente sobre os diferentes aspectos da ciência. Por exemplo, há uma similaridade muito grande entre os itens 2 (Construção humana) e 4 (Ciência \& Cultura); entre os itens 1 (Linear) e 10 (Refutacionista); e entre os itens 5 (Neutralidade) e 9 (Comprovação). Quer dizer, as respostas ao item que avaliava se a ciência é entendida como um processo contínuo de construção humana são praticamente as mesmas atribuídas ao item que inferia se o participante percebe que a ciência é influenciada por aspectos sociais, culturais e políticos. 
(a)
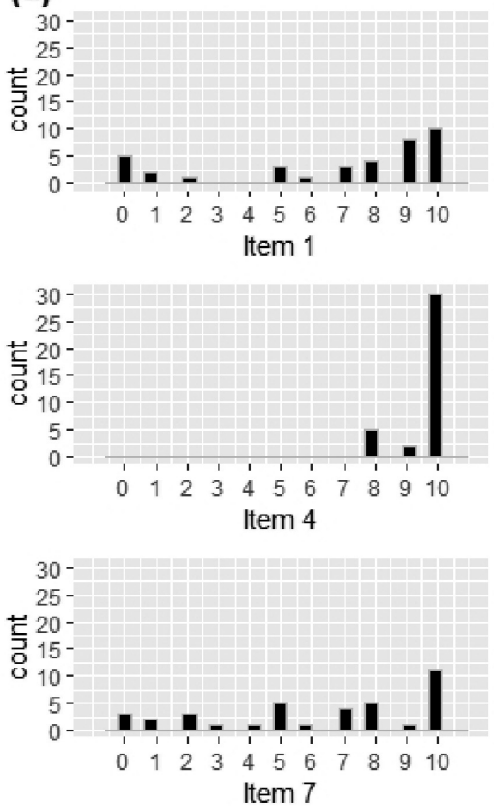

(b)
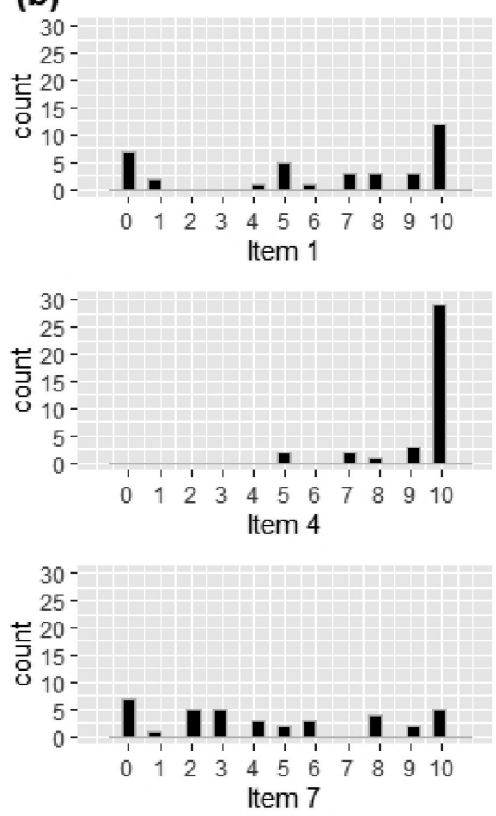

Questionário inicial
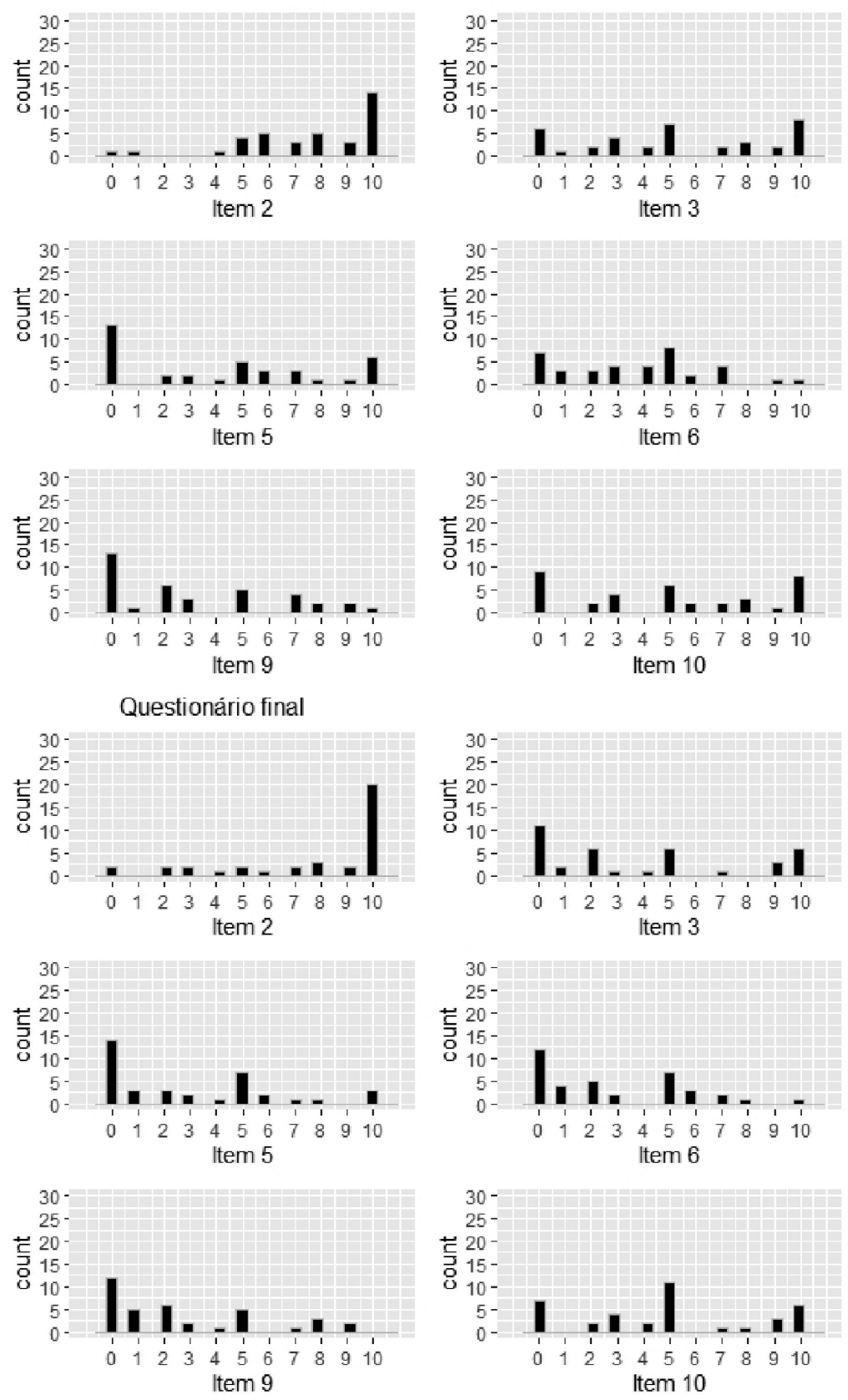

Figura 2: Histograma com a frequência de resposta dos participantes do curso no pré (a) e no pós-teste (b).

Da mesma maneira, os participantes responderam da forma muito similar aos itens sobre a linearidade do processo científico e sobre a possibilidade de abandono de uma teoria a partir de uma refutação experimental; revelando que os participantes associam muito fortemente esses dois aspectos da visão mais tradicional da ciência. Ademais, há também uma vinculação muito forte entre as ideias tradicionais de que a ciência é neutra e de que todo conhecimento científico é comprovado empiricamente. Cabe ainda destacar, a partir do maior distanciamento no mapa, a total oposição entre esse último entendimento de senso comum da ciência e a visão contemporânea sobre a relação entre ciência e sociedade.

A análise do distanciamento dos itens no mapa da Figura 3 sugere que, após a realização do curso, os participantes efetivamente conseguiram sistematizar as diferentes visões de ciência. É importante destacar que o EMD realizado não permite afirmar se os participantes possuem uma outra concepção de ciência, é possível mostrar que após o curso os participantes começaram a responder de maneira muito similar aos itens de mesmo conteúdo temático, sugerindo que essa intervenção proporcionou um bom cenário sobre as diferentes 

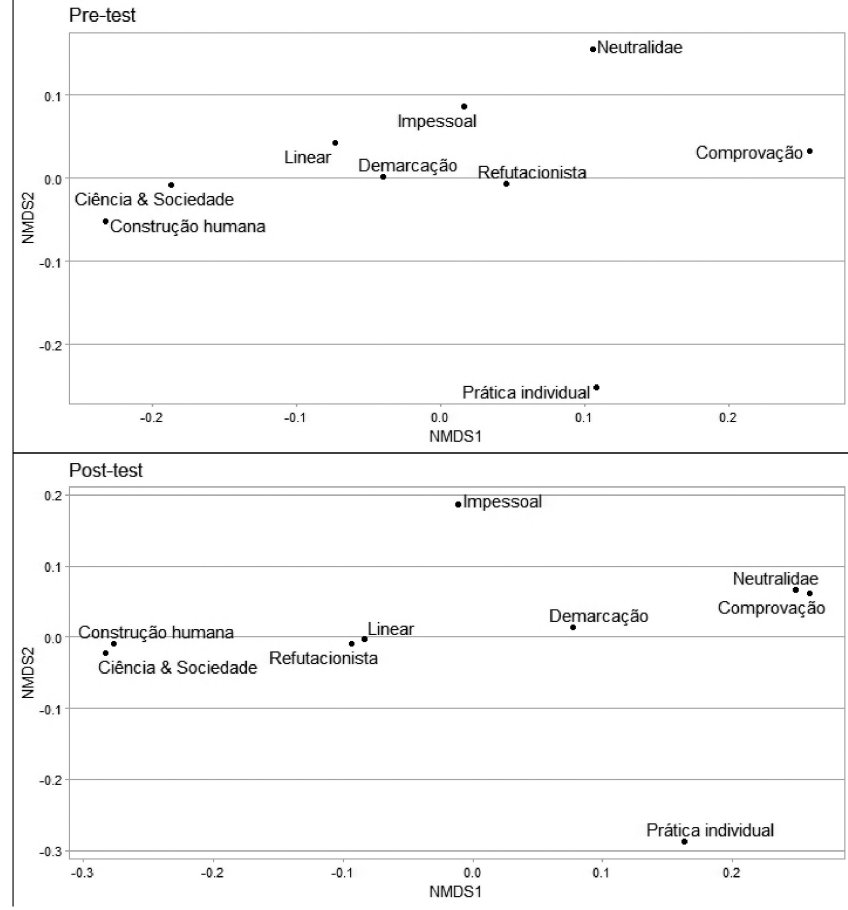

Figura 3: Análise de similaridade dos itens do questionário antes (pré) e depois (pós) da realização do curso.

concepções de ciência, suas principais similitudes e idiossincrasias.

\section{Considerações Finais}

As indicações sobre a importância de se inserir discussões históricas e epistemológicas na educação básica e na formação científica é antiga. Apesar disso, relatos da literatura apontam que a inserção de disciplinas sobre esses tópicos na licenciatura não promove uma mudança significativa na atuação docente [36], nem essas discussões são transpostas para educação básica, mesmo quando o professor se alinha com uma perspectiva epistemológica contemporânea [57]. Uma possível explicação para isso é que as discussões epistemológicas são mobilizadas de forma isolada no currículo, não dialogando com as disciplinas técnicas - reforçando o abismo entre a formação científica e pedagógica, característica da história das licenciaturas no país [37. A legislação contemporânea e diferentes estudos sobre formação de professores têm apontado justamente a necessidade do desenvolvimento da identidade da licenciatura [58].

Buscando contribuir para a superação dessa fragmentação, nesse trabalho, apresentamos uma análise de um curso de extensão no qual temas da história da Astronomia são traduzidos e interpretados à luz de diferentes visões epistemológicas. Nosso objetivo era viabilizar que os alunos confrontassem suas concepções de ciência com os diferentes posicionamentos epistemológicos.

Para avaliação da intervenção, aplicamos um préteste e um pós-teste, constituído por um conjunto de dez enunciados sobre a ciência, sobre os quais os participantes deveriam expressar o nível de concordância em uma escala likert. Nossos resultados mostram que, inicialmente, havia uma baixa similaridade entre as respostas dos participantes, indicando a existência de concordância em relação a visões concorrentes sobre a natureza da ciência. Após o curso, a similaridade aumentou, sugerindo que os participantes passaram a se posicionar de forma mais coerente, concordando com características de uma mesma visão epistemológica e se afastando de visões concorrentes.

Não se deve com isso achar que um curso de extensão é suficiente para promover uma mudança significativa e duradoura nas concepções epistemológicas dos participantes. Tudo que podemos concluir, a partir dos resultados, é que, ao final do curso, as visões passam a ser mais consistentes. Entendemos que unidades didáticas com esse propósito devem permear todo currículo de licenciatura e ser reforçado em cursos de formação de professores. Ademais, é necessário que esses docentes e futuros docentes também participem de espaço que fomentem a reflexão sobre a prática docente e sobre a inserção desses tópicos na prática docente. Tal proposta exige uma pesquisa que foge ao escopo desse trabalho. De qualquer forma, esperamos mostrar que a inserção de tópicos de epistemologia de forma integrada aos conteúdos técnicos (nesse caso, temas da Astronomia e Astrofísica), mesmo em pouco tempo, possui um impacto significativo na organização das concepções dos participantes - o que motiva a proposição de novas intervenções e pesquisas que avancem no sentido de construir um currículo de licenciatura que integre a formação pedagógica e técnica.

\section{Agradecimentos}

Os autores agradecem à professora Neusa Massoni por suas contribuições com o desenvolvimento da pesquisa.

\section{Material Suplementar}

O seguinte material suplementar está disponível online: Apêndice 1 - Material de Apoio para a Intervenção Didática.

Apêndice 2 - Pesquisa de Opinião/Concepções.

\section{Referências}

[1] S.B. Kreuger e P. Ramos, em: XI Encontro Nacional de de Pesquisa em Educação em Ciências (Florianópolis, 2017).

[2] R. Vilanova, Ciência \& Educação 21, 177 (2015).

[3] F. Pinhão e I. Martins, Ens. Pesqui. Educ. Ciênc. 18, 9 (2016).

[4] I. Linsingen, Ciência \& Ensino 1 (2007).

[5] B. Latour, Jamais Fomos Modernos (Editora 34, São Paulo, 2013). 
[6] B. Latour, Cogitamus: Seis Cartas sobre as Humanidades Científicas (Editora 34, São Paulo, 2016).

[7] L.H. Sasseron e A.M.P. Carvalho, Investig. em Ensino Ciências 16, 59 (2011).

[8] D. Auler e D. Delizoicov, Ens. Pesqui. Educ. Ciênc. 3, $122(2001)$.

[9] A. Chassot, Rev. Bras. Educ. 22, 89 (2003).

[10] W.L.P. Santos, Rev. Bras. Educ. 12, 474 (2007).

[11] W.L.P. Santos e E.F. Mortimer, Ens. Pesqui. Educ. Ciênc. 2, 110 (2000).

[12] A. Bagdonas, J. Zanetic e I. Gurgel, Rev. Bras. História da Ciência 7, 242 (2014).

[13] T.C.M. Forato, M. Pietrocola e R.D.A. Martins, Cad. Bras. Ensino Física 28, 27 (2011).

[14] J. Guisasola, J.M. Almudí e C. Furió, Sci. Educ. 14, 321 (2005).

[15] M.R. Matthews, Educ. Philos. Theory 20, 67 (1988).

[16] F.J. Rutherford, em: Science Education and Culture: The Contribution of History and Philosophy of Science, editado por F. Bevilacqua, E. Giannetto e M.R. Matthews (Springer, Dordrecht, 2001), p. 41.

[17] M. Weinstein, Sci. Educ. 92, 389 (2008).

[18] G.S. Aikenhead, em: ESERA Conference (Noordwijkerhout, 2003).

[19] F. Abd-El-Khalick e N.G. Lederman, Int. J. Sci. Educ. 22, 665 (2000).

[20] E.S. Teixeira, I.M. Greca e O. Freire, Sci. Educ. 21, 771 (2012).

[21] J.L. Kincheloe e K. Tobin, Cult. Stud. Sci. Educ. 4, 513 (2009).

[22] A. Johansson, S. Andersson, M. Salminen-Karlsson e M. Elmgren, Cult. Stud. Sci. Educ. 13, 205 (2018).

[23] N.W. Lima, P.A.V. Vazata, A.G. Moraes, F. Ostermann e C.J. H. Cavalcanti, Rev. Bras. Pesqui. em Educ. em Ciências 19, 155 (2019).

[24] A. Junges e N.T. Massoni, Rev. Bras. Pesqui. em Educ. em Ciências 18, 455 (2018).

[25] J. Vrieze, Bruno Latour, a veteran of the 'science wars', has a new mission, disponível em: https://www.science. org/content/article/bruno-latour-veteran-science-warshas-new-mission

[26] N.W. Lima e M.M. Nascimento, Cad. Bras. Ensino Física 36, 589 (2019).

[27] H. Schiffer e A. Guerra, Sci. Educ. 24, 409 (2015).

[28] G.L.F. Batista, J.M.H. Drummond e D.B. Freitas, Cad. Bras. Ensino Física 32, 663 (2015).

[29] D.S. Fonseca, J.M.H. Drummond, W.C. Oliveira e D.B. Freitas, Cad. Bras. Ensino Física 12, 145 (2017).

[30] A.P.B. Silva e A. Guerra, História da Ciência e Ensino: Fontes primárias e propostas para sala de aula (Editora Livraria da Física, São Paulo, 2015).

[31] R. Karam e O. Krey, Sci. Educ. 24, 661 (2015).

[32] M.A. Moreira, N.T. Massoni e F. Ostermann, Rev. Bras. Ensino Física 29, 127 (2007).

[33] A.F.P. Martins, Cad. Bras. Ensino Física 24, 112 (2007).

[34] C.B. Moura e A. Guerra, Rev. Bras. Pesqui. em Educ. em Ciências 16, 749 (2016).

[35] A. Alves-Brito, N. Massoni, A. Guerra e J.R. Macedo, Rev ABPN 12, 282 (2020).
[36] F.A. Carvalho, Investigação sobre potencialidades de estratégias que visam transformar concepções epistemológicas e desenvolver predisposições didáticas em estudantes de Licenciatura em Física. Dissertação de Mestrado, Universidade Federal do Rio Grande do Sul, Porto Alegre (2017).

[37] R.S. Araujo e D.M. Vianna, Rev. Bras. Ensino Física 32, 4403 (2010).

[38] A. Chalmers, O que é ciência afinal (Brasiliense, São Paulo, 1993).

[39] J.V. Wertsch, Vygotsky and the Social Formation of Mind (Harvard University Press, Cambridge, 1985).

[40] M. Bakhtin, Os Gêneros do Discurso (Editora 34, São Paulo, 2016).

[41] J.V. Wertsch, Voices of the Mind: A Sociocultural Approach to Mediated Action (Harvard University Press, Cambridge, 1993).

[42] K. Popper, Conjecturas e Refutações (Editora Universidade de Brasília, Brasília, 2008).

[43] I. Lakatos, The Methodology of Scientific Research programmes (Cambridge University Press, Cambridge, 1978).

[44] B. Latour, P. Jensen, T. Venturini, S. Grauwin e D. Boullier, Br. J. Sociol. 63, 590 (2012).

[45] T. Venturini, Public Underst. Sci. 21, 796 (2012).

[46] L.J. Cronbach, Psychometrika 16, 297 (1951).

[47] R.F. DeVellis, Scale development: Theory and applications (SAGE Publications, Los Angeles, 2016).

[48] R.K. McKinley, T. Manku-Scott, A.M. Hastings, D.P. French e R. Baker, BMJ 314, 193 (1997).

[49] R.A. Johnson e D.W. Wichern, Applied multivariate statistical analysis (Prentice Hall, Upper Saddle River, 2002).

[50] T.F. Cox e M.A.A. Cox, Multidimensional scaling (Chapman and Hall/CRC, Boca Raton, 2000).

[51] M.M. Nascimento, E. Antunes Júnior, C. Cavalcanti e F. Ostermann, Rev. Bras. Pesqui. em Educ. em Ciências 19, 775 (2019).

[52] C.A. Santos, Aplicação da análise multidimensional e da análise de agrupamentos hierárquicos ao mapeamento cognitivo de conceitos físicos. Dissertação de Mestrado, Universidade Federal do Rio Grande do Sul, Porto Alegre (1978).

[53] I.M. Greca e M.A. Moreira, Rev. Bras. Pesqui. em Educ. em Ciências 1 (2001).

[54] T.R. Hilger, Representações sociais da física quântica. Dissertação de Mestrado, Universidade Federal do Rio Grande do Sul, Porto Alegre (2009).

[55] F.W. Young, Multidimensional scaling: History, theory, and applications (Psychology Press, New York, 2013).

[56] R Core Team, R: A language and environment for statistical computing, versão 3.4.3 (Vienna, 2015).

[57] N.T. Massoni e M.A. Moreira, Ciência \& Educação 20, 595 (2014).

[58] N.T. Massoni, M.E. Bruckmann e A. Alves-Brito, Rev. Educ. Mais 4, 512 (2020). 